The Astrophysical Journal, 670:1510-1517, 2007 December 1

(C) 2007. The American Astronomical Society. All rights reserved. Printed in U.S.A.

\title{
ANHARMONIC SPECTROSCOPIC STUDY OF THE GROUND ELECTRONIC STATE OF VARIOUS $\mathrm{C}_{4}$ RADICAL ISOTOPOMERS
}

\author{
M. L. Senent, ${ }^{1}$ H. Massó, ${ }^{1}$ And M. Hochlaf ${ }^{2}$ \\ Received 2007 April 26; accepted 2007 August 1
}

\begin{abstract}
Quartic force fields for the ground electronic states of the most stable $\mathrm{C}_{4}$ radical isomers $\left[1-\mathrm{C}_{4}\left(X^{3} \Sigma_{g}^{-}\right)\right.$and r- $\left.\mathrm{C}_{4}\left(X^{1} A_{g}\right)\right]$ are computed at the same level of theory. These computations are performed using interaction configuration ab initio methods and the cc-pVTZ basis set. These force fields on symmetry-adapted coordinates are derived from full six-dimensional potential energy surfaces generated close to their equilibrium geometries. For both isomers, sets of spectroscopic parameters of the most abundant isotopic varieties are determined with perturbation theory. This includes rotational constants, harmonic wavenumbers, anharmonic wavenumbers for the fundamentals, and some overtones, combination modes, and l-doubling terms. Finally, our results are compared with experimental data measured with different techniques that allow us to discuss assignments of previous astrophysical observations. Specifically, we are focusing in predicting frequencies for the low bendings allowing understanding patterns detected with far-infrared techniques.
\end{abstract}

Subject headings: astrochemistry — infrared: ISM — ISM: molecules — molecular data

\section{INTRODUCTION}

During the last decade, tetracarbon has been one of the chemical species that has attracted major interest for the astrophysics community, since it is expected to be among the small $\mathrm{C}_{n}$ radicals present in carbon-rich sources (Cernicharo et al. 2000). Small $\mathrm{C}_{n}$ chains can be important intermediates for chemical reactions in the gas phase, and they had been related to the observed diffuse interstellar bands (Douglas 1977).

Consequently, the search for carbon chains in interstellar sources is so frequent. The presence of small carbon clusters such as $\mathrm{C}_{3}$ (Cernicharo et al. 2000) suggests the existence in the same sources of other compounds of similar chemical properties. Recently, the astrophysicists of DAMIR (Cernicharo et al. 2002) have observed in Sgr B2, IRC +10216, CRL 2688, CRL 618, and NGC 7027 a pattern of bands at $57 \mu \mathrm{m}\left(174 \mathrm{~cm}^{-1}\right)$ with the Infrared Space Observatory unspecified in the database. It consists of a complex feature with four subcomponents at 57.0, 57.6, 57.9, and $58.2 \mu \mathrm{m}$, which cannot be identified to any far-infrared spectra of the most abundant carbon chains, for instance, $\mathrm{C}_{3}, \mathrm{C}_{5}$. Several other experimentally well-characterized molecular candidates presenting low bending modes lying in the $160-220 \mathrm{~cm}^{-1}$ energy range were checked without success. Instead, the antisymmetric deformations of the $\mathrm{C}_{4} \mathrm{H}$ and $\mathrm{C}_{4}$ radicals were proposed. However, very few data are available in the literature for these two molecules, especially for $\mathrm{C}_{4}$. The low chemical stability of this radical made the development of experiments in the laboratory for its investigation by classical techniques difficult. Many of its properties must be deduced using theoretical predictions. A definitive assignment of the astrophysical band implies collecting new spectroscopic parameters in the database for astrophysics.

Previous experimental works dealing with this and other small $\mathrm{C}_{n}$ terms were summarized in the review of Van Order \& Saykally (1998). It turns out from this review the paucity of data relative to $\mathrm{C}_{4}$ and that many aspects involving its spectroscopic properties are misinterpreted. Briefly, the infrared (IR) spectrum of $1-\mathrm{C}_{4}$

\footnotetext{
1 Departamento de Astrofísica Molecular e Infrarroja (DAMIR), IEM-CSIC, C/Serrano 121, 28006 Madrid, Spain; senent@damir.iem.csic.es.

${ }^{2}$ Theoretical Chemistry Group, University of Marne-la-Vallée, Champs sur Marne, F-77454 Marne-la-Vallée, Cedex 2, France.
}

trapped in Ar matrix by Shen \& Graham (1989) and the gasphase IR spectrum of $1-C_{4}$ by Heath \& Saykally (1991) have identified the antisymmetric CC stretching $\nu_{3}$ fundamental at $1543.4 \mathrm{~cm}^{-1}$ in matrix and at $1548.9 \mathrm{~cm}^{-1}$ in the gas phase. Later studies performed in the Ne matrix (Smith et al. 1994), in solid neon (Forney et al. 1995), and in Ne, ortho- $\mathrm{D}_{2}$, and para- $\mathrm{H}_{2}$ matrices ( Tam et al. 1997) placed the origin $\nu_{3}$ band at $1547 \mathrm{~cm}^{-1}$, whereas the cooled $\mathrm{Kr}$ matrix $\mathrm{C}_{4}$ isolation study of Szczepanski et al. (1996) has located it at lower energies $\left(1539 \mathrm{~cm}^{-1}\right)$. The situation is, however, rather critical for the other modes which are known with relatively large error bars, making the unequivocal assignment of some interstellar bands difficult. Indeed, the gasphase symmetric stretching $\left(\nu_{1}\right)$ and the trans-bending $\left(\nu_{4}\right)$ fundamentals have been determined by photoelectron spectroscopy to be $2032 \pm 50 \mathrm{~cm}^{-1}$ (Arnold et al. 1991) and $2057 \pm 50 \mathrm{~cm}^{-1}$ (Xu et al. 1997) and $339 \pm 55 \mathrm{~cm}^{-1}$ (Arnold et al. 1991) and $323 \pm 50 \mathrm{~cm}^{-1}$ (Xu et al. 1997), respectively. For the $\nu_{4}$ fundamental (Gakwaya et al. 2004; Moazzen-Ahmadi \& Thong 1995) diode laser spectrometry gives the origin band at $353 \pm 15 \mathrm{~cm}^{-1}$. Concerning the cis bending $\left(\nu_{5}\right)$, the Fourier transform far-IR spectroscopy applied to $1-\mathrm{C}_{4}$ trapped in $\mathrm{Ar}$ matrix placed it at $172.4 \mathrm{~cm}^{-1}$ (Withey et al. 1991). Later on, Moazzeen-Ahmadi et al. (1994) have shifted the $\nu_{5}$ to lower energies (at $160.4 \mathrm{~cm}^{-1}$ ) based on their analysis of the pattern of the l-doubling for the $5_{0}^{1}$ band. Experimentally, nothing is said in the literature concerning the CC middle stretching mode $\nu_{2}$. Theoretically, previous ab initio investigations (Botschwina 1997, 2006; Watts et al.1992; Martin et al. 1996) provide more or less accurate anharmonic wavenumbers for $1-C_{4}$. The $\omega_{1}$ mode harmonic fundamental has been calculated by Botschwina (1997) at $2109 \mathrm{~cm}^{-1}$ at the coupled cluster [RCCSD(T)/336 cGTOs] level of the ory. Watts et al. (1992) have determined the far-IR harmonic frequencies to be at $474 \mathrm{~cm}^{-1}\left(\omega_{4}\right)$ and $203 \mathrm{~cm}^{-1}\left(\omega_{5}\right)$ using the RCCSD(T)/cc-pVTZ. Using many-body perturbation theory (MBPT), $\omega_{4}$ is computed as $390 \mathrm{~cm}^{-1}$ and $\left(\omega_{5}\right) 172 \mathrm{~cm}^{-1}$. More recently, Botschwina (2006) has computed the low-frequency $\nu_{5}$ fundamental to be at $171.1 \mathrm{~cm}^{-1}$ using a $\operatorname{RCCSD}(\mathrm{T})$ cis-bending one-dimensional potential. In contrast to $1-\mathrm{C}_{4}$, no spectroscopic data are found for $\mathrm{r}_{-} \mathrm{C}_{4}$ in the literature except for the theoretical work of Martin et al. (1996), who deduced the anharmonic force field of $\mathrm{r}^{-} \mathrm{C}_{4}\left(X^{1} A_{g}\right)$ at the RCCSD(T) level. 
Recently, we were presenting electronic structure calculations giving an insight into the stable isomers of the $\mathrm{C}_{4}$ and their lowest electronic states (Massó et al. 2006). Calculations were achieved using monoconfigurational [CCSD(T)] and multiconfigurational (MRCI/CASSCF) methods. We localized four stationary points (three minima and one saddle point) in the surface, two of them corresponding to two isomers of similar stabilities: one linear $\left[1-\mathrm{C}_{4}\left(X^{3} \Sigma_{g}^{-}\right)\right]$and one cyclic $\left[\mathrm{r}-\mathrm{C}_{4}\left(X^{1} A_{g}\right)\right]$. A third structure of $\mathrm{C}_{2 \mathrm{v}}$ symmetry, d-C $\mathrm{C}_{4}\left(X^{1} A_{1}\right)$, was found, although it is not obvious if it is an isomer or a transition state. As stated there, it is the best candidate for being the third isomer of $\mathrm{C}_{4}$ observed experimentally (Kella et al. 1993). The fourth stationary point corresponds to an unstable square structure lying between the two conformers of the rhombic isomer. A preliminary exploration of the potential energy surfaces in order to establish possible isomerization processes showed that these isomers are separated by large potential barriers, high enough to allow for the treatment of each form separately for its spectroscopy. Accordingly, the sixdimensional potential energy surfaces (6D-PESs) are mapped here, in symmetry-adapted coordinates, for the two most stable isomers of $\mathrm{C}_{4}$, close to their equilibrium geometries. These 6D-PESs are derived as full quartic force fields allowing the deduction of a set of spectroscopic data for these two isomers using standard perturbation theory. In what follows we focus mainly on the bendings in order to discuss the tentative assignment of the $57 \mu \mathrm{m}$ astrophysical band to $\mathrm{C}_{4}$ and therefore its presence in Sgr B2, IRC +10216 , CRL 2688, CRL 618, and NGC 7027. It is worth noting that most of previous calculations on carbon chains have been performed within the harmonic approximation. However, a very anharmonic bending pattern is established experimentally for $\mathrm{C}_{3}$ (Cernicharo et al. 2000). Moreover, strong couplings are expected between the modes leading to pronounce anharmonic behavior of the PES along the corresponding coordinates. For both reasons, the harmonic approximation is useless for the PES topology that is expected for small $\mathrm{C}_{n}$ clusters, a fortiori for $\mathrm{C}_{4}$.

\section{COMPUTATIONAL DETAILS}

Both static and dynamical electronic correlations play a crucial role for $\mathrm{C}_{4}$ (Massó et al. 2006). Hence, our electronic computations were done using the complete active space self-consistent field (CASSCF; Werner \& Knowles 1985; Knowles \& Werner $1985)$ followed by the internally contracted multireference configuration interaction (MRCI) approaches (Werner \& Knowles 1988; Knowles \& Werner (1988). For CASSCF, various different active spaces selected using orbital energy and symmetry criteria have been explored. For data presented here, we were using the largest space possible where the active spaces was defined containing ten orbitals; eight orbitals (four core orbitals and four valence orbitals) have been considered doubly occupied in all the configurations, but they have been optimized. In MRCI calculations, all configurations having a weight greater than 0.03 in the CI expansion of the CASSCF wave functions were taken as a reference resulting in more than $7 \times 10^{6}$ uncontracted CSFs to be treated in each symmetry of the $\mathrm{C}_{2 \mathrm{v}}$ point group. All valence electrons were correlated. For MRCI, the Davidson correction $(\mathrm{MRCI}+\mathrm{Q})$ was also included. The electronic calculations have been performed using the MOLPRO program Werner \& Knowles (2002). For carbon, the $s p d f$ cc-pVTZ basis set of Dunning (1989) was used. The $6 \mathrm{D}-\mathrm{PESs}$ of $1-\mathrm{C}_{4}\left(X^{3} \Sigma_{g}^{-}\right)$and $\mathrm{r}-\mathrm{C}_{4}\left(X^{1} A_{g}\right)$ were mapped close to their equilibrium geometries given in Massó et al. (2006). These 6D-PESs are derived as quartic force fields in symmetry adapted coordinates (see $\S 3$ for more details). The main group of spectroscopic parameters (fundamentals, overtones, several combination band positions, etc.) has been calcu- lated with perturbation theory applied on the quadratic, cubic, and quartic force fields derived from the 6D-PESs and the new FORTRAN code FIT-ESPEC. ${ }^{3}$ This new code performs a linear fit of the energies on internal coordinates to a Taylor series followed by a minimization for determining the most stable geometry. The final force field is defined in dimensionless normal coordinates. For accurate computations of anharmonicities, the calculated potential contains four mode-coupling terms. For comparison, harmonic frequencies were also determined using the coupled cluster methods including the perturbative treatment of the connected triple substitutions RCCSD( T) (Knowles et al. 1993), and all valence electrons were correlated at the optimized geometry structures defined in Massó et al. (2006) and the standard options implemented in the MOLPRO package.

\section{RESULTS AND DISCUSSION}

The local PESs for the ground electronic states of the two isomers $\left[1-\mathrm{C}_{4}\left(X^{3} \Sigma_{g}^{-}\right)\right.$and $\left.\mathrm{r}-\mathrm{C}_{4}\left(X^{1} A_{g}\right)\right]$ are calculated for determining their spectroscopic parameters considering the anharmonic effects. As pointed out in $\S 1$, deep potential wells are separating each isomer, allowing the treatment of them separately for their spectroscopy. The surfaces are therefore mapped around their respective equilibrium geometries, i.e., external CC distances $=1.2960 \AA$ and middle $\mathrm{CC}=1.3167 \AA$ in a linear configuration [i.e., for $1-\mathrm{C}_{4}\left(X^{3} \Sigma_{g}^{-}\right)$], and $\mathrm{R}_{31}$ (the shorter intracyclic $\mathrm{CC}$ bound $)=1.5201 \AA, \mathrm{R}_{12}=1.4414 \AA$ for a planar $\mathrm{D}_{2 \mathrm{~h}}$ structure [i.e., $\mathrm{r}-\mathrm{C}_{4}\left(X^{1} A_{g}\right)$; Massó et al. 2006].

These calculations were done using the CASSCF approach followed by the MRCI + Q and the cc-pVTZ basis set. Several reasons justify the employment of $\mathrm{MRCI}+\mathrm{Q}$ for the complete spectroscopic study of the $\mathrm{C}_{4}$ radical, although it is accompanied by the loss of size consistency, which is an important property in the determination of PESs. First, harmonic preliminary studies of $1-C_{4}$ show that the monoconfigurational methods, such as $\operatorname{RCCSD}(\mathrm{T})$, are unsuccessful in predicting some frequencies and, therefore, of their anharmonic couplings to the low-frequency bending modes of interest here. This is the case at least for the $\nu_{3}$ fundamental of the linear form (antisymmetric CC stretching mode). Such methods are leading to an overestimation of the corresponding wavenumbers. Indeed, the $\mathrm{RCCSD}(\mathrm{T}) / \mathrm{cc}-\mathrm{pVTZ}$ harmonic wavenumbers are computed $\omega_{1}=2109, \omega_{2}=937, \omega_{3}=$ 1938, $\omega_{4}=381$, and $\omega_{5}=176 \mathrm{~cm}^{-1}$. The $\nu_{3}$ is off by about $400 \mathrm{~cm}^{-1}$ from the experimental determinations $\left(1548-1539 \mathrm{~cm}^{-1}\right.$; Heath \& Saykally 1991; Smith et al. 1994; Forney et al. 1995; Tam et al. 1997; Szczepanski et al. 1996). A large and significant improvement of this frequency is obtained with the $\operatorname{UCCSD}(\mathrm{T})$ and CASSCF methods (1554.6 and $1669.9 \mathrm{~cm}^{-1}$, respectively). This is because of (1) symmetry breaking problems not fully solved at the CC level of theory and (2) underestimation of static correlation. Second, the electronic ground wave functions of the $\mathrm{C}_{4}$ isomers show a strong multiconfigurational character where the statistical weight of the HF configuration on the CASSCF wave function is relatively low, and it varies strongly by changing, for example, the distances from equilibrium. Only MRCI allows for the correction of all these discrepancies, and it is believed to give the most reliable data.

\subsection{Anharmonic Force Fields for $\mathrm{C}_{4}$}

For $1-\mathrm{C}_{4}\left(X^{3} \Sigma_{g}^{-}\right), 1050 \mathrm{MRCI}+\mathrm{Q}$ nonredundant energies were computed. For the generation of the grid of points, symmetry and

\footnotetext{
3 FIT-ESPEC is a FORTRAN code for calculating spectroscopic parameters from a force field in internal coordinates (M. L. Senent 2007).
} 


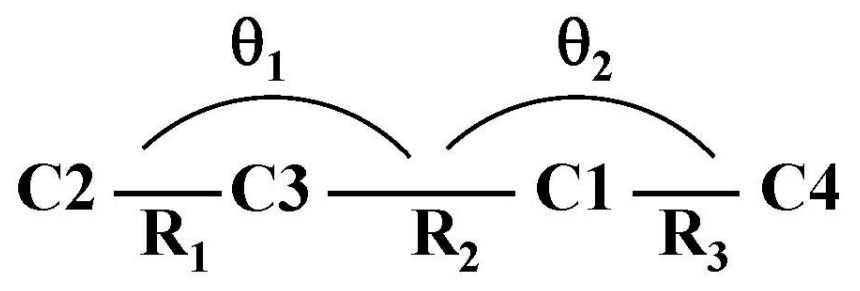

FIG. 1.- Independent internal coordinates of $1-\mathrm{C}_{4}$.

energy criteria have been taken into consideration to select a set of geometries depending on six internal coordinates: three bond distances, $\mathrm{R}_{1}$ (external CC), $\mathrm{R}_{2}$ (middle $\mathrm{CC}$ ), and $\mathrm{R}_{3}$ (external $\mathrm{CC})$; two in-plane angles, $\Theta_{1}$ and $\Theta_{2}$, which are defined in Figure 1; and a dihedral angle, $\tau=\mathrm{C} 4 \mathrm{C} 1 \mathrm{C} 3 \mathrm{C} 2$. The seven independent symmetry vibrational coordinates corresponding to a linear molecule are generated using the definition of Hoy et al. (1972) for the linear angles. Bond distances and linear angles lying in the $X-Z$ and $Y-Z$ planes are used to define the simplest adapted symmetry coordinates

$$
\begin{aligned}
\mathrm{S}_{1}=\mathrm{R}_{2}, & \mathrm{~S}_{2}=\frac{1}{\sqrt{2}}\left(\mathrm{R}_{1}+\mathrm{R}_{3}\right), \quad \mathrm{S}_{3}=\frac{1}{\sqrt{2}}\left(\mathrm{R}_{1}-\mathrm{R}_{3}\right), \\
\mathrm{S}_{i}^{z s}=\frac{1}{\sqrt{2}}\left(\theta_{1}^{z s}+\theta_{2}^{z s}\right), & (i, s)=(4, x),(4, y), \\
\mathrm{S}_{i}^{z s}=\frac{1}{\sqrt{2}}\left(\theta_{1}^{z s}-\theta_{2}^{z s}\right), & (i, s)=(5, x),(5, y) .
\end{aligned}
$$

Our grid allows the definition of the PES up to about $12,000 \mathrm{~cm}^{-1}$; $\mathrm{R}_{1}, \mathrm{R}_{2}$, and $\mathrm{R}_{3}$ vary in the ranges $1.24-1.36,1.26-1.36$, and 1.24$1.36 \AA$, respectively, and the angular coordinates change from $0^{\circ}$ to $85^{\circ}$.

For $\mathrm{r}-\mathrm{C}_{4}\left(X^{1} A_{g}\right)$, the six internal coordinates (five bond distances $\left[\mathrm{R}_{12}, \mathrm{R}_{14}, \mathrm{R}_{23}, \mathrm{R}_{34}\right.$, and the diagonal $\mathrm{R}_{13}$ ] and a torsional coordinate $\tau$ [the dihedral angle between plans C2 C1 C3 and C1 C3 C4; cf. Fig. 2]) were selected to define the grid. Our grid covers the nuclear geometries where $1.40 \AA \leq \mathrm{R}_{12} \leq 1.72 \AA$, $1.47 \AA \leq \mathrm{R}_{13} \leq 1.59 \AA$, and $0^{\circ} \leq \tau \leq+20^{\circ}$. MRCI $+\mathrm{Q}$ energies were computed defining the PES up to about $10,000 \mathrm{~cm}^{-1}$. Our internal coordinates allow for the definition of the six symmetry coordinates as (Linguerri et al. 2005)

$$
\begin{array}{r}
\mathrm{S}_{1}=\frac{1}{\sqrt{4}}\left(\mathrm{R}_{12}+\mathrm{R}_{14}+\mathrm{R}_{23}+\mathrm{R}_{34}\right), \quad \mathrm{S}_{2}=\mathrm{R}_{13} \\
\mathrm{~S}_{3}=\frac{1}{\sqrt{4}}\left(\mathrm{R}_{12}+\mathrm{R}_{14}-\mathrm{R}_{23}-\mathrm{R}_{34}\right), \quad \mathrm{S}_{4}=\tau \\
\mathrm{S}_{5}=\frac{1}{\sqrt{4}}\left(\mathrm{R}_{12}-\mathrm{R}_{14}-\mathrm{R}_{23}+\mathrm{R}_{34}\right) \\
\mathrm{S}_{6}=\frac{1}{\sqrt{4}}\left(\mathrm{R}_{12}-\mathrm{R}_{14}+\mathrm{R}_{23}-\mathrm{R}_{34}\right) .
\end{array}
$$

For both isomers, the MRCI + Q energies were fitted to a full dimensional Taylor series, for which the coefficients are the forces

$$
\begin{aligned}
V\left(q_{1}, q_{2}, \ldots, q_{n}\right)= & \sum_{i=1}^{n} \sum_{j=1}^{n} \frac{1}{2} f_{i j} q_{i} q_{j}+\sum_{i=1}^{n} \sum_{j=1}^{n} \sum_{k=1}^{n} \frac{1}{6} f_{i j k} q_{i} q_{j} q_{k} \\
& +\sum_{i=1}^{n} \sum_{j=1}^{n} \sum_{k=1}^{n} \sum_{l=1}^{n} \frac{1}{24} f_{i j k l} q_{i} q_{j} q_{k} q_{l},
\end{aligned}
$$

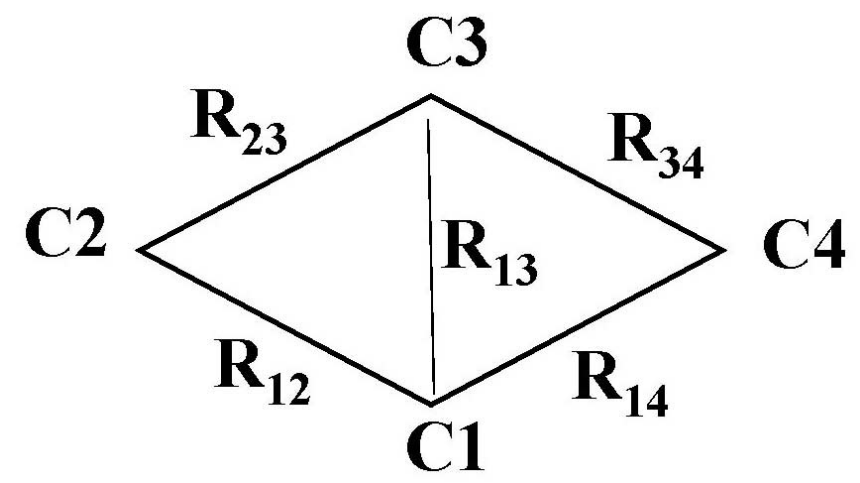

Fig. 2.- Independent internal coordinates of $\mathrm{r}-\mathrm{C}_{4}$.

where $q_{i}=\mathrm{S}_{i}-\mathrm{S}_{i}^{\mathrm{REF}} . \mathrm{S}^{\mathrm{REF}}$ refers to the reference geometry used for fitting which are chosen to be the $S_{i}$ equilibrium values. This results in 76 and 48 force field coefficients to be optimized for 1- $\mathrm{C}_{4}\left(X^{3} \Sigma_{g}^{-}\right)$and for $\mathrm{r}-\mathrm{C}_{4}\left(X^{1} A_{g}\right)$, respectively. The rms deviations of the fits were $43 \mathrm{~cm}^{-1}$ and $\mathrm{R}^{2}=1.00000$. The corresponding quartic anharmonic force fields are listed in Table 1. Structural parameters of the reference geometry are those calculated and shown in Table 1 of Massó et al. (2006). The minimum for the linear isomer corresponds to a linear structure with $\mathrm{R}_{1}=$ $\mathrm{R}_{3}=1.3167 \AA$ and $\mathrm{R}_{2}=1.2960 \AA$, whereas the parameters for the rhombic isomer minimum are $R_{12}=1.4510 \AA$ and $R_{13}=$ $1.5204 \AA$ A. Our distances should be accurate to within $0.01 \AA$.

\subsection{Spectroscopic Constants and Anharmonic Fundamentals}

$$
\text { 3.2.1. } 1-\mathrm{C}_{4}\left(X^{3} \Sigma_{g}^{-}\right)
$$

Table 2 lists anharmonicity terms for linear $\mathrm{C}_{4}$ deduced from our quartic force field. This table shows that some of the $x_{i j}$ are quite large, especially those corresponding to the asymmetric stretching and those between the bending and the stretching (e.g., $x_{14}$ is equal to $-40.065 \mathrm{~cm}^{-1}$ ). This is the signature of the strong coupling between these modes, invalidating the use of the harmonic approximation. Table 3 gives the structural parameters and the spectroscopic data for $1-\mathrm{C}_{4}\left(X^{3} \Sigma_{g}^{-}\right)$. The data deduced from calculations achieved for various isotopomers containing ${ }^{13} \mathrm{C}$, the second most abundant carbon isotope existing in the interstellar medium (ISM; abundance ratio ${ }^{13} \mathrm{C} /{ }^{12} \mathrm{C} \sim 1 / 45$ ), are also presented. This table shows the rotational constants at equilibrium $\left(B_{e}\right)$ and the rotational constants that include the vibrational corrections for the zero-point vibrational energy $\left(B_{0}\right)$ and for the five fundamentals $\left(B \nu_{i}\right)$. For ${ }^{12} \mathrm{C}_{4}$, our $B_{0}$ value differs by less than $0.0025 \mathrm{~cm}^{-1}$ from the $B_{0}$ constant deduced from the diode laser absorption study of Moazzen-Ahmadi et al. (1994). The differences between our $B \nu_{i}$ values for the $\nu_{3}, \nu_{4}$, and $\nu_{5}$ fundamentals and those deduced with the gas-phase measurements of MoazzenAhmadi et al. (1994) and Moazzen-Ahmadi \& Thong (1995) are about $1 \%$, which is reflecting the $0.01 \AA$ accuracy on our computed equilibrium distances. This good accord validates our 6D-PES and the use of perturbation theory for the deduction of accurate data for $1-\mathrm{C}_{4}$. The rotational constants for the most abundant isotopomers of $1-\mathrm{C}_{4}$ listed in Table 3 are predictive in nature and should be of similar accuracy.

Table 3 lists the harmonic and anharmonic wavenumbers of $1-\mathrm{C}_{4}$ deduced from our MRCI+Q 6D-PES and perturbation theory. The stretchings are computed $\omega_{1}=2157.2, \omega_{2}=911.1$, and $\omega_{3}=$ $1529.1 \mathrm{~cm}^{-1}$. The corresponding anharmonic wavenumbers are $\nu_{1}=2040.6, \nu_{2}=883.1$, and $\nu_{3}=1496.9 \mathrm{~cm}^{-1}$. The symmetric 
TABLE 1

Anharmonic Force Fields of the Ground Electronic States of 1-C 4 and r-C 4 Computed from the MrCi/CASSCF/cc-pVTZ PESs

\begin{tabular}{|c|c|c|c|c|c|c|c|}
\hline \multicolumn{4}{|c|}{$1-\mathrm{C}_{4}$} & \multicolumn{4}{|c|}{$\mathrm{r}-\mathrm{C}_{4}$} \\
\hline \multicolumn{4}{|c|}{$f_{i j}$} & \multicolumn{4}{|c|}{$f_{i j}$} \\
\hline $\begin{array}{l}f_{11} \ldots \ldots \ldots \ldots \ldots . . . \\
f_{22} \ldots \ldots \ldots \ldots \ldots . . . \\
f_{33} \ldots \ldots \ldots \ldots . . . \\
f_{44} \ldots \ldots \ldots \ldots \ldots . . .\end{array}$ & $\begin{array}{r}10.301 \\
9.376 \\
8.265 \\
0.123\end{array}$ & $\begin{array}{l}f_{55} \ldots \ldots \ldots \ldots \ldots \ldots \\
f_{21} \ldots \ldots \ldots \ldots \ldots \ldots\end{array}$ & $\begin{array}{l}0.174 \\
0.207\end{array}$ & 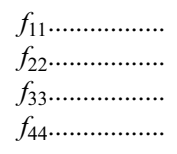 & $\begin{array}{l}6.158 \\
5.179 \\
1.761 \\
0.218\end{array}$ & $\begin{array}{l}f_{55} \ldots \ldots \ldots \ldots \ldots \ldots \\
f_{66} \ldots \ldots \ldots \ldots \ldots \ldots . . \\
f_{21} \ldots \ldots \ldots \ldots \ldots \ldots . . .\end{array}$ & $\begin{array}{r}4.117 \\
5.119 \\
-1.753\end{array}$ \\
\hline \multicolumn{4}{|c|}{$f_{i j k}$} & \multicolumn{4}{|c|}{$f_{i j k}$} \\
\hline $\begin{array}{l}f_{111} \ldots \ldots \ldots \ldots \ldots \\
f_{222} \ldots \ldots \ldots \ldots \ldots \\
f_{112} \ldots \ldots \ldots \ldots . . . \\
f_{221} \ldots \ldots \ldots \ldots \ldots \\
f_{331} \ldots \ldots \ldots \ldots . . \\
f_{332} \ldots \ldots \ldots \ldots \ldots \\
f_{441} \ldots \ldots \ldots \ldots . .\end{array}$ & $\begin{array}{r}-103.168 \\
-80.538 \\
-1.956 \\
-1.097 \\
-15.910 \\
-30.179 \\
-0.483\end{array}$ & $\begin{array}{l}f_{442} \ldots \ldots \ldots \ldots \ldots . . . \\
f_{551} \ldots \ldots \ldots \ldots \ldots \\
f_{552} \ldots \ldots \ldots \ldots \ldots . . . \\
f_{345} \ldots \ldots \ldots \ldots \ldots \ldots . . .\end{array}$ & $\begin{array}{l}-0.592 \\
-0.970 \\
-0.419 \\
-0.806\end{array}$ & $\begin{array}{l}f_{111} \ldots \ldots \ldots \ldots . . \\
f_{222} \ldots \ldots \ldots \ldots \ldots \\
f_{112} \ldots \ldots \ldots \ldots . . . \\
f_{221} \ldots \ldots \ldots \ldots \ldots \\
f_{331} \ldots \ldots \ldots \ldots \ldots \\
f_{332} \ldots \ldots \ldots \ldots . . . \\
f_{441} \ldots \ldots \ldots \ldots \ldots\end{array}$ & $\begin{array}{r}-19.065 \\
-7.905 \\
9.784 \\
-8.970 \\
1.631 \\
13.371 \\
-0.440\end{array}$ & $\begin{array}{l}f_{442} \ldots \ldots \ldots \ldots \\
f_{551} \ldots \ldots \ldots \ldots \\
f_{552} \ldots \ldots \ldots \ldots \\
f_{661} \ldots \ldots \ldots \ldots . . \\
f_{662} \ldots \ldots \ldots \ldots \\
f_{653} \ldots \ldots \ldots \ldots\end{array}$ & $\begin{array}{r}1.930 \\
-24.210 \\
-14.837 \\
-20.869 \\
9.415 \\
-7.518\end{array}$ \\
\hline \multicolumn{4}{|c|}{$f_{i j k l}$} & \multicolumn{4}{|c|}{$f_{i j k l}$} \\
\hline$f_{1111} \ldots \ldots \ldots \ldots$ & 1041.016 & $f_{5533} \ldots \ldots \ldots \ldots$ & -13.877 & $f_{1111} \ldots \ldots \ldots \ldots \ldots$ & 72.352 & $f_{5533} \ldots \ldots \ldots \ldots . . .$. & -14.625 \\
\hline$f_{2222} \ldots \ldots \ldots \ldots$ & 1377.446 & $f_{4455} \ldots \ldots \ldots \ldots \ldots$ & 0.003 & $f_{2222} \ldots \ldots \ldots \ldots \ldots$ & -173.259 & 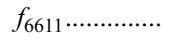 & 33.209 \\
\hline$f_{3333} \ldots \ldots \ldots \ldots$ & 609.449 & $f_{555^{\prime} 5^{\prime}} \ldots \ldots \ldots \ldots$ & -2.818 & $f_{3333} \ldots \ldots \ldots \ldots \ldots$ & 17.650 & $f_{6633} \ldots \ldots \ldots \ldots . . .$. & 23.638 \\
\hline$f_{4444} \ldots \ldots \ldots \ldots$ & 0.511 & $f_{1112} \ldots \ldots \ldots \ldots \ldots$ & 40.056 & $f_{4444} \ldots \ldots \ldots \ldots \ldots$ & 0.039 & 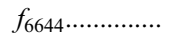 & -0.286 \\
\hline$f_{5555} \ldots \ldots \ldots \ldots . . .$. & 0.448 & $f_{2221} \ldots \ldots \ldots \ldots$ & 152.576 & $f_{5555} \ldots \ldots \ldots \ldots \ldots$ & 3.479 & 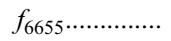 & 15.939 \\
\hline$f_{2211} \ldots \ldots \ldots \ldots$ & 164.895 & $f_{3321} \ldots \ldots \ldots \ldots$ & 112.047 & $f_{6666} \ldots \ldots \ldots \ldots . .$. & -47.082 & $f_{1112} \ldots \ldots \ldots \ldots . . .$. & -97.567 \\
\hline$f_{3311} \ldots \ldots \ldots \ldots$ & 522.105 & $f_{4421} \ldots \ldots \ldots \ldots$ & 0.326 & $f_{2211} \ldots \ldots \ldots \ldots$ & 38.766 & $f_{2221} \ldots \ldots \ldots \ldots$ & 47.667 \\
\hline$f_{3322} \ldots \ldots \ldots \ldots$ & -968.828 & $f_{5521} \ldots \ldots \ldots \ldots \ldots$ & -15.319 & $f_{3311} \ldots \ldots \ldots \ldots \ldots$ & -35.021 & $f_{3321} \ldots \ldots \ldots \ldots$ & 5.904 \\
\hline$f_{4411} \ldots \ldots \ldots \ldots$ & 2.297 & $f_{4455^{\prime}} \ldots \ldots \ldots \ldots$ & 1.713 & $f_{3322} \ldots \ldots \ldots \ldots \ldots$ & 38.172 & 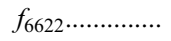 & 92.249 \\
\hline$f_{4422 \ldots \ldots \ldots \ldots . . .}$ & -14.825 & $f_{1345} \ldots \ldots \ldots \ldots \ldots$ & -208.344 & $f_{4411} \ldots \ldots \ldots \ldots \ldots$ & 0.263 & $f_{4421} \ldots \ldots \ldots \ldots \ldots$ & -2.274 \\
\hline$f_{4433} \ldots \ldots \ldots \ldots$ & 13.742 & $f_{2345} \ldots \ldots \ldots \ldots \ldots$ & 75.271 & $f_{4422} \ldots \ldots \ldots \ldots \ldots$ & 6.681 & $f_{5521} \ldots \ldots \ldots \ldots \ldots$ & 21.959 \\
\hline$f_{444^{\prime} 4^{\prime}} \ldots \ldots \ldots \ldots$ & 0.677 & & & $f_{4433} \ldots \ldots \ldots \ldots \ldots$ & -0.059 & $f_{6621} \ldots \ldots \ldots \ldots \ldots$ & -40.586 \\
\hline$f_{5511} \ldots \ldots \ldots \ldots$ & -4.265 & & & $f_{5511} \ldots \ldots \ldots \ldots \ldots$ & 31.008 & $f_{6531} \ldots \ldots \ldots \ldots \ldots$ & -2.274 \\
\hline$f_{5522 \ldots \ldots \ldots \ldots . . .}$ & -3.461 & & & $f_{5522} \ldots \ldots \ldots \ldots \ldots$ & -15.998 & $f_{6532} \ldots \ldots \ldots \ldots \ldots$ & 21.959 \\
\hline
\end{tabular}

NотE.-These terms are of the form $f_{i j}$, where $i$ and $j$ correspond to the $\mathrm{S}$ coordinates defined in eqs. (1) and (2). All values are in units of aJ.

CC stretch $\nu_{1}$ is located at $2032 \pm 50$ and $2057 \pm 50 \mathrm{~cm}^{-1}$ using photoelectron spectroscopy (Arnold et al. 1991; Xu et al. 1997), which agrees quite well with our value, and it is coherent with the previous calculations of Botschwina $\left(1997 ; 2109 \mathrm{~cm}^{-1}\right)$ and Watts et al. $\left(1992 ; 2156 \mathrm{~cm}^{-1}\right)$. For the central CC stretching $\nu_{2}$, our value agrees well with those computed previously, and it should be more reliable since it is derived from a full quartic force field. However, it is quite certain that our $\nu_{3}$ wavenumber of $1469.9 \mathrm{~cm}^{-1}$ is quite low (the difference with gas-phase measurements reach $53 \mathrm{~cm}^{-1}$; see Table 3 ), since the symmetry breaking problem emphasized above is not fully resolved, even at the MRCI level. We do believe that larger computations in which all CASSCF CSFs are used to generate the MRCI active space and basis set larger than cc-pVTZ are needed for better describing the PES along this nuclear motion. Let us now consider the bending modes, which are extremely important in order to interpret astrophysical observations with the far-IR telescope. Our anharmonic MRCI value for the trans-bending $\left(\nu_{4}\right)$ is $314.4 \mathrm{~cm}^{-1}$, which falls in the ranges of the experimental determinations, i.e., $339 \pm 55 \mathrm{~cm}^{-1}$ (Arnold et al. 1991), $323 \pm 50 \mathrm{~cm}^{-1}$ (Xu et al. 1997), and $352 \pm 15 \mathrm{~cm}^{-1}$ (Gakwaya et al. 2004; Moazzen-Ahmadi \& Thong 1995). This value should be accurate to within $10 \mathrm{~cm}^{-1}$, thus reducing the error bars for this fundamental. The cis bending $\left(\nu_{5}\right)$, which is measured at $160 \pm 4 \mathrm{~cm}^{-1}$ in the gas phase by Moazzen-Ahmadi et al. (1994) by means of diode laser spectroscopy, is computed to be $162.2 \mathrm{~cm}^{-1}$ at the cc-pVTZ/MRCI level of theory. In a recent paper, Botschwina (2006) provides a value of $171 \mathrm{~cm}^{-1}$ for this bending mode using a cis-bending $\operatorname{CCSD}(\mathrm{T})$ one-dimensional potential, which neglects interactions with the stretching modes.

Finally, Table 3 gives the vibrational data for the most abundant isotopomers of $1-{ }^{12} \mathrm{C}_{4}$ and the wavenumbers of some overtones and combination modes. Isotopic substitutions produce larger effects on the stretching modes, whereas the isotopic shifts of the bending modes are less significant. For the symmetric $\nu_{1}$ stretching, a single carbon substitution displaces the band by an amount of $32 \mathrm{~cm}^{-1}$ (from 2040.6 to $2008.4 \mathrm{~cm}^{-1}$ ). For $\nu_{2}$, this variation is less significant (from 883.1 to $868.5 \mathrm{~cm}^{-1}$ ). In the case of $\nu_{3}$, the calculated displacement from ${ }^{12} \mathrm{C}_{4}$ to ${ }^{13} \mathrm{C}^{12} \mathrm{C}^{12} \mathrm{C}^{12} \mathrm{C}$ of $16 \mathrm{~cm}^{-1}$ coincides with the observed displacement of $15 \mathrm{~cm}^{-1}$ (Shen \& Graham 1989), since mass effects are less related to static correlation. The data in Table 3 for the other isotopomers and

TABLE 2

Anharmonic Constants $x_{i j}$ and $g_{i j}$ of $1-\mathrm{C}_{4}$ Computed FROM THE MRCI/CASSCF/cc-pVTZ FORCE FIELD

Anharmonic Constants $\left(\mathrm{cm}^{-1}\right)$

\begin{tabular}{llllllllll}
\hline$x_{11}$ & -8.858 & & & & & & & & \\
$x_{22}$ & 3.403 & $x_{12}$ & -12.505 & & & & & & \\
$x_{33}$ & 16.594 & $x_{13}$ & -109.590 & $x_{23}$ & -41.252 & & & & \\
$x_{44}$ & -1.873 & $x_{14}$ & -40.065 & $x_{24}$ & -0.857 & $x_{34}$ & 26.339 & & \\
$x_{55}$ & -0.612 & $x_{15}$ & 2.245 & $x_{25}$ & -7.038 & $x_{35}$ & -16.282 & $x_{45}$ & 5.641 \\
$g_{44}$ & 2.457 & $g_{55}$ & 0.662 & $g_{45}$ & 0.358 & & & & \\
\hline
\end{tabular}


TABLE 3

Structural and Perturbation Theory Spectroscopic Parameters of the Ground Electronic State of the Isotopomers of $1-\mathrm{C}_{4}$ COMPUTED FROM THE MRCI/CASSCF/cc-pVTZ PES

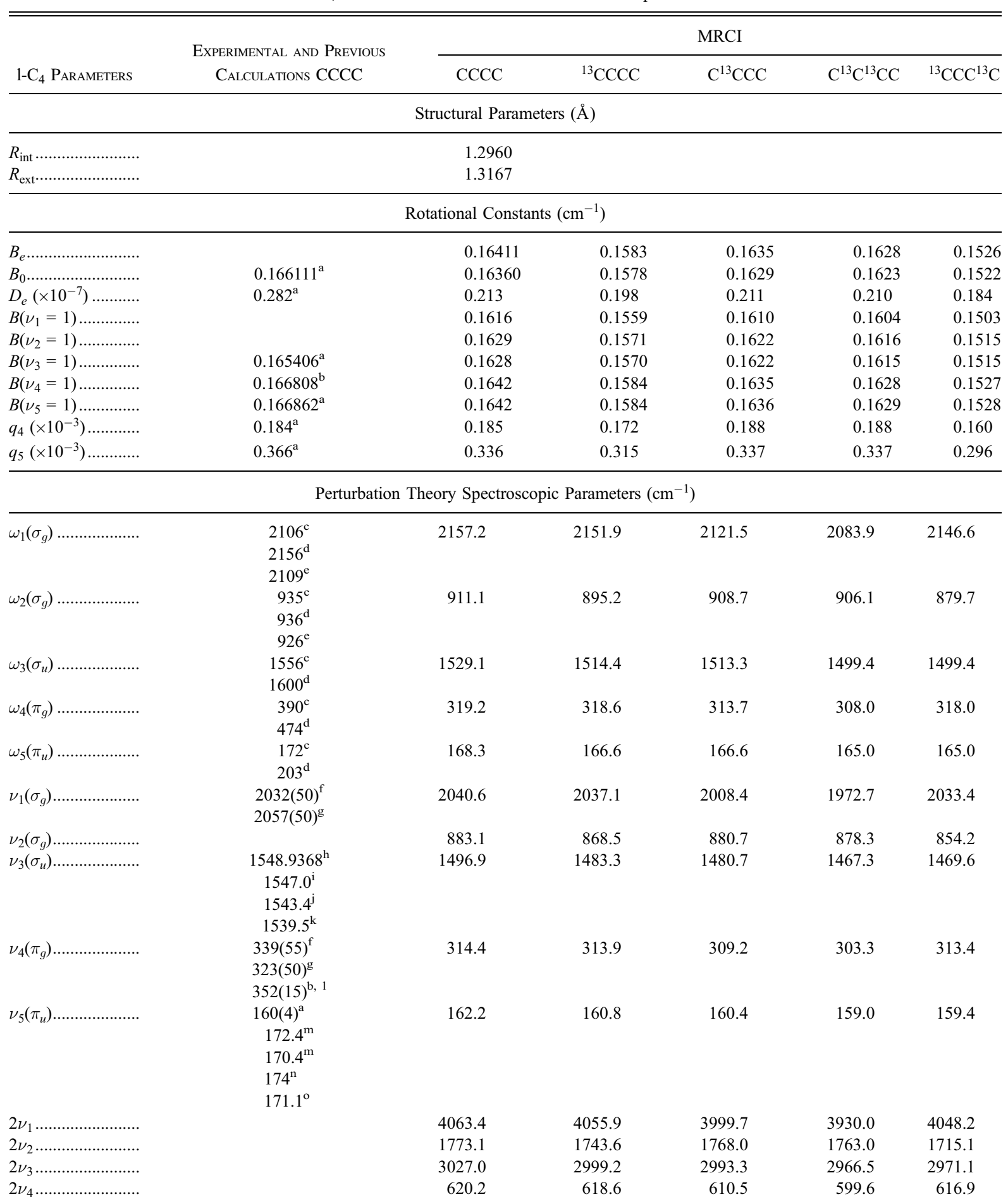


TABLE 3-Continued

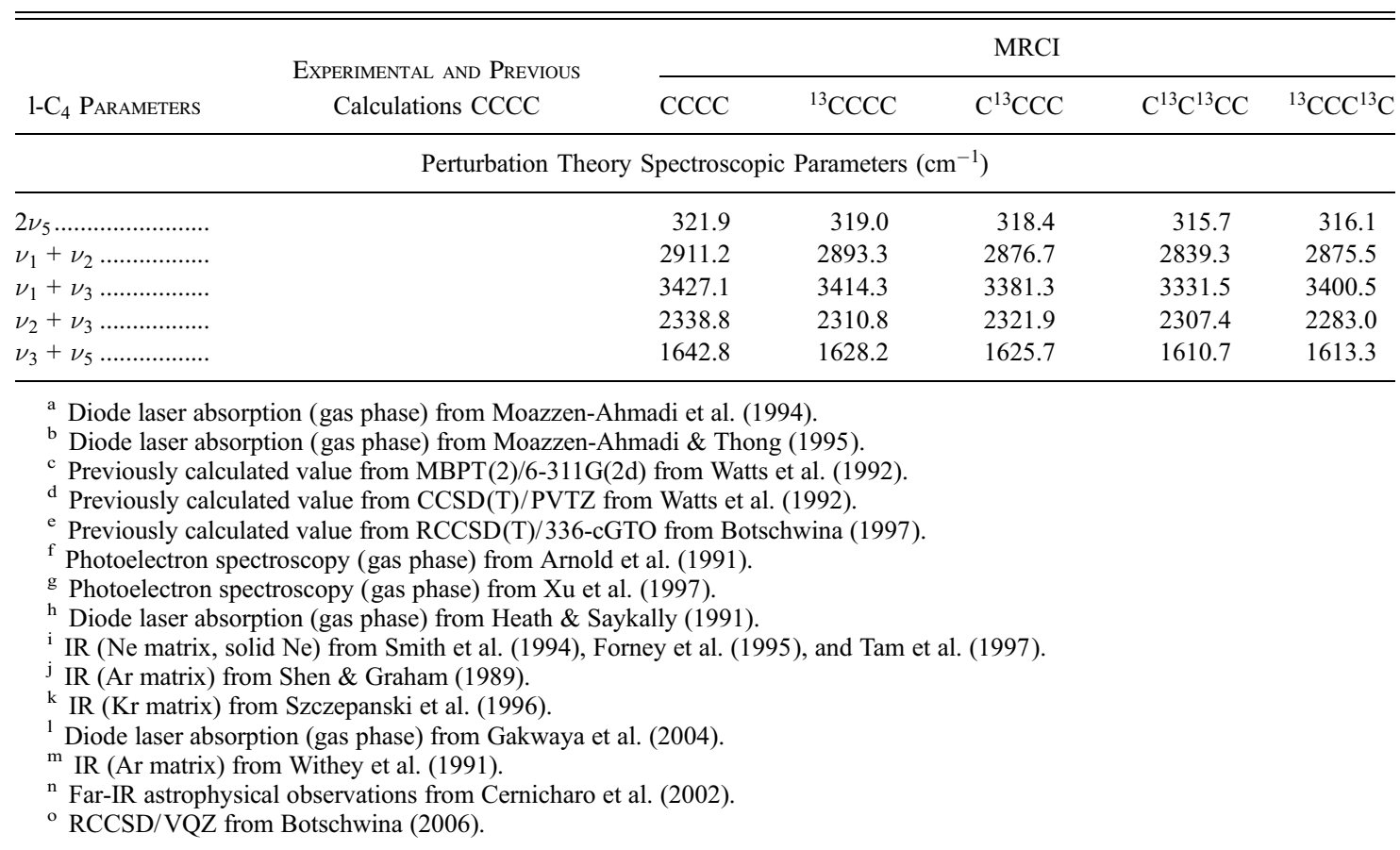

those of the unknown overtones and combination modes should be helpful in their identification in the laboratory and ISM.

$$
\text { 3.2.2. } \mathrm{r}-\mathrm{C}_{4}\left(X^{1} A_{g}\right)
$$

To our knowledge, experimental spectroscopic works on $\mathrm{r}-\mathrm{C}_{4}$ are nonexistent. Theoretically and except for the work of Martin et al. (1996) performed with the monoconfigurational RCCSD(T) method, no data are available in the literature dealing with this isomer, which is believed to be as stable as the linear form (Massó et al. 2006). For this reason, data in Table 4 represent predictions for this species and its isotopomers. Indeed, Table 4 lists the harmonic and anharmonic frequencies and several spectroscopic parameters of the rhombic isomer of $\mathrm{C}_{4}$, determined from the force field discussed in $\S 3.1$. Calculations have been performed using perturbation theory in dimensionless normal coordinates derived from the 6D-PES.

When we consider the rotational constants, they are computed to be $A_{e}=1.2149, B_{e}=0.4599$, and $C_{e}=0.3336 \mathrm{~cm}^{-1}$ for the most abundant isotopomer of $\mathrm{r}^{-} \mathrm{C}_{4}$. When the vibration-rotation terms are taken into account, the corresponding $A_{v}, B_{v}$, and $C_{v}$ constants are changing by $0.01-0.02 \mathrm{~cm}^{-1}$. Readers are referred to Table 4 for more details.

The two lowest fundamental frequencies, which are IR active (intensities 42 and $90 \mathrm{kcal} \mathrm{mol}^{-1}$ ), are calculated to be $279.2 \mathrm{~cm}^{-1}$ $\left(\nu_{4}\left[\mathrm{~b}_{1 \mathrm{u}}\right]\right.$; out-of-plane) and $522.5 \mathrm{~cm}^{-1}\left(\nu_{5}\left[\mathrm{~b}_{2 \mathrm{u}}\right]\right.$, in-plane bending). The symmetric stretchings are computed to be 1285.9 and $949.4 \mathrm{~cm}^{-1}$, whereas the nonsymmetric ones have been calculated to lie at $981.5\left(\nu_{3}\right)$ and $1378.0 \mathrm{~cm}^{-1}\left(\nu_{6}\right)$. Finally, this table shows that the effect of the carbon substitution is not really significant for the bending modes (isotopic shifts less than $5 \mathrm{~cm}^{-1}$ ), since the rhombic form is more rigid and its flexibility is surely lower compared to the linear form. However, differences between $\mathrm{r}^{12} \mathrm{C}_{4}$ and $\mathrm{r}^{13} \mathrm{C}^{12} \mathrm{C}_{3}$ reach $10 \mathrm{~cm}^{-1}$ for the stretchings.

\subsubsection{Comparison with Astrophysical Observations}

We turn now to the comparison of our data with the band observed with $I S O$ at $174 \mathrm{~cm}^{-1}$, which has been attributed to the $\nu_{5}$ bending mode of $1-\mathrm{C}_{4}$ (Cernicharo et al. 2002). Table 3 shows that the previous measurements for this band range from $160 \mathrm{~cm}^{-1}$ (Moazzen-Ahmadi et al. 1994) in the gas phase up to 172.4 and $170 \mathrm{~cm}^{-1}$ in cooled Ar matrixes (Withey et al. 1991). Our large calculations are giving a value of $162.2 \mathrm{~cm}^{-1}$, consistent with the gas-phase value. Nevertheless, even here, a final statement about this band is hardly possible since our calculations are expected to be accurate to within $10 \mathrm{~cm}^{-1}$ for such low-frequency modes. This band cannot be attributed to the isoenergetic stable isomer $\mathrm{r}-\mathrm{C}_{4}$, since the low harmonic bending frequencies are computed to be well above $200 \mathrm{~cm}^{-1}$, far from the detected $174 \mathrm{~cm}^{-1}$ band. Nevertheless, even the assignment of this band to $1-\mathrm{C}_{4}\left(\nu_{5}\right)$ is questionable when one considers the shape of the ISO observed pattern at $174 \mathrm{~cm}^{-1}$. In Cernicharo et al. (2002), it has been proposed that the complexity may be understood assuming a molecular system with a nonzero spin-orbit coupling of $A_{\mathrm{SO}}=4 \mathrm{~cm}^{-1}$ (or better put, a spin-spin constant of $4 \mathrm{~cm}^{-1}$ ). Since the ground state of $\mathrm{C}_{4}$ is of the ${ }^{3} \Sigma_{g}^{-}$species, a spin-orbit constant so high should be related to the proximity of the lowest electronic states. For this reason, we have performed ab initio calculations including second-order spin-orbit and spin-spin effects (Lefebvre-Brion et al. 2004). The first excited state of $1-\mathrm{C}_{4}$ is the $A^{1} \Delta_{g}$ state located at $0.33 \mathrm{eV}$ above the $X$-state (Massó et al. 2006). However, the $\left\langle A^{1} \Delta_{g}\left|H^{\mathrm{SO}}\right| X^{3} \Sigma_{g}^{-}\right\rangle$integral gives no contribution for $\Delta \Lambda= \pm 2$. The following excited state is the $B{ }^{1} \Sigma_{g}^{+}$state, which results from the $\pi^{2}$ electron configuration as the $X$ - and $A$-states. At the cc-pVTZ/CASSCF level of theory and using the formula developed in Lefebvre-Brion \& Field (2004, p. 201) the spin-spin slitting for the $X$-state is computed to be in the range $0.17-0.2 \mathrm{~cm}^{-1}$. The effect is too small for $\mathrm{C}_{4}$ to justify the assignment of the observed band using ab initio calculations. Other molecular candidates for the $57 \mu \mathrm{m}$ should be tested (M. L. Senent et al. 2008, in preparation).

\section{CONCLUSIONS}

In the present work, valuable spectroscopic data on the lowest isomers of $\mathrm{C}_{4}$ are computed using accurate ab initio methods and 
TABLE 4

Structural and Perturbation Theory Spectroscopic Parameters of the Ground Electronic State OF THE ISOTOPOMERS OF r-C 4 COMPUTED FROM THE MRCI/CASSCF/cc-pVTZ PES

\begin{tabular}{|c|c|c|c|c|c|c|}
\hline \multirow[b]{2}{*}{$\mathrm{r}-\mathrm{C}_{4}$ Parameters } & \multirow[b]{2}{*}{ CCCC (MARTIN ET AL. 1996) ${ }^{a}$} & \multicolumn{5}{|c|}{ THIS WORK ${ }^{\mathrm{b}}$} \\
\hline & & $\mathrm{CCCC}$ & ${ }^{13} \mathrm{C}_{1} \mathrm{CCC}$ & $\mathrm{C}^{13} \mathrm{C}_{2} \mathrm{CC}$ & ${ }^{13} \mathrm{C}_{1}{ }^{13} \mathrm{C}_{2} \mathrm{CC}$ & ${ }^{13} \mathrm{C}_{1} \mathrm{C}^{13} \mathrm{C}_{3} \mathrm{C}$ \\
\hline \multicolumn{7}{|c|}{ Structural Parameters $(\AA)$} \\
\hline$R_{12} \ldots \ldots \ldots \ldots \ldots \ldots \ldots \ldots$ & 1.4540 & 1.4510 & & & & \\
\hline$R_{13} \ldots \ldots \ldots \ldots \ldots \ldots \ldots \ldots \ldots \ldots \ldots \ldots$ & 1.5186 & 1.5204 & & & & \\
\hline \multicolumn{7}{|c|}{ Rotational Constants $\left(\mathrm{cm}^{-1}\right)$} \\
\hline$A_{e} \ldots \ldots \ldots \ldots \ldots \ldots \ldots \ldots \ldots$ & & 1.2149 & 1.1673 & 1.2149 & 1.1673 & 1.1212 \\
\hline$B_{e} \ldots \ldots \ldots \ldots \ldots \ldots \ldots \ldots$ & & 0.4599 & 0.4599 & 0.4419 & 0.4419 & 0.4600 \\
\hline$C_{e} \ldots \ldots \ldots \ldots \ldots \ldots \ldots \ldots$ & & 0.3336 & 0.3299 & 0.3240 & 0.3205 & 0.3262 \\
\hline$\kappa \ldots \ldots \ldots \ldots \ldots \ldots \ldots \ldots \ldots$ & & -0.7134 & -0.6895 & -0.7354 & -0.7134 & -0.6636 \\
\hline$D_{J}\left(\times 10^{-6}\right) \ldots \ldots \ldots \ldots \ldots$ & & 0.2129 & 0.2115 & 0.1979 & 0.1966 & 0.2102 \\
\hline$D_{J K}\left(\times 10^{-6}\right) \ldots \ldots \ldots \ldots$ & & 0.6571 & 0.6466 & 0.6173 & 0.6092 & 0.6312 \\
\hline$D_{K}\left(\times 10^{-5}\right) \ldots \ldots \ldots \ldots$ & & 0.4553 & 0.4167 & 0.4608 & 0.4220 & 0.3780 \\
\hline$d_{J}\left(\times 10^{-6}\right) \ldots \ldots \ldots \ldots \ldots$ & & 0.592 & 0.599 & 0.540 & 0.547 & 0.606 \\
\hline$d_{K}\left(\times 10^{-5}\right) \ldots \ldots \ldots \ldots$ & & 0.7157 & 0.6890 & 0.6858 & 0.6611 & 0.6627 \\
\hline$A_{0} \ldots \ldots \ldots \ldots \ldots \ldots \ldots \ldots \ldots$ & & 1.2178 & 1.1702 & 1.2177 & 1.1700 & 1.1243 \\
\hline$B_{0} \ldots \ldots \ldots \ldots \ldots \ldots \ldots$ & & 0.4570 & 0.4570 & 0.4391 & 0.4391 & 0.4570 \\
\hline$C_{0} \ldots \ldots \ldots \ldots \ldots \ldots \ldots \ldots$ & & 0.3319 & 0.3282 & 0.3223 & 0.3189 & 0.3245 \\
\hline$A\left(\nu_{1}=1\right) \ldots \ldots \ldots \ldots \ldots$ & & 1.2142 & 1.1668 & 1.2140 & 1.1666 & 1.1214 \\
\hline$B\left(\nu_{1}=1\right) \ldots \ldots \ldots \ldots \ldots \ldots$ & & 0.4566 & 0.4565 & 0.4387 & 0.4387 & 0.4565 \\
\hline$C\left(\nu_{1}=1\right) \ldots \ldots \ldots \ldots \ldots$ & & 0.3315 & 0.3278 & 0.3221 & 0.3186 & 0.3241 \\
\hline$A\left(\nu_{2}=1\right) \ldots \ldots \ldots \ldots \ldots$ & & 1.2184 & 1.1705 & 1.2184 & 1.1705 & 1.1245 \\
\hline$B\left(\nu_{2}=1\right) \ldots \ldots \ldots \ldots \ldots$ & & 0.4567 & 0.4567 & 0.4387 & 0.4387 & 0.4567 \\
\hline$C\left(\nu_{2}=1\right) \ldots \ldots \ldots \ldots \ldots$ & & 0.3267 & 0.3226 & 0.3179 & 0.3140 & 0.3185 \\
\hline$A\left(\nu_{3}=1\right) \ldots \ldots \ldots \ldots \ldots$ & & 1.2028 & 1.1559 & 1.2027 & 1.1558 & 1.1108 \\
\hline$B\left(\nu_{3}=1\right) \ldots \ldots \ldots \ldots \ldots$ & & 0.4543 & 0.4544 & 0.4365 & 0.4366 & 0.4545 \\
\hline$C\left(\nu_{3}=1\right) \ldots \ldots \ldots \ldots \ldots$ & & 0.3329 & 0.3298 & 0.3227 & 0.3198 & 0.3266 \\
\hline$A\left(\nu_{4}=1\right) \ldots \ldots \ldots \ldots \ldots$ & & 1.1982 & 1.1520 & 1.1978 & 1.1516 & 1.1076 \\
\hline$B\left(\nu_{4}=1\right) \ldots \ldots \ldots \ldots \ldots$ & & 0.4571 & 0.4571 & 0.4392 & 0.4392 & 0.4571 \\
\hline$C\left(\nu_{4}=1\right) \ldots \ldots \ldots \ldots \ldots$ & & 0.3334 & 0.3298 & 0.3238 & 0.3204 & 0.3261 \\
\hline$A\left(\nu_{5}=1\right) \ldots \ldots \ldots \ldots$ & & 1.2602 & 1.2099 & 1.2601 & 1.2099 & 1.1617 \\
\hline$B\left(\nu_{5}=1\right) \ldots \ldots \ldots \ldots \ldots$ & & 0.4572 & 0.4572 & 0.4393 & 0.4392 & 0.4572 \\
\hline$C\left(\nu_{5}=1\right) \ldots \ldots \ldots \ldots \ldots$ & & 0.3325 & 0.3289 & 0.3229 & 0.3195 & 0.3252 \\
\hline$A\left(\nu_{6}=1\right) \ldots \ldots \ldots \ldots \ldots$ & & 1.2191 & 1.1714 & 1.2190 & 1.1712 & 1.1254 \\
\hline$B\left(\nu_{6}=1\right) \ldots \ldots \ldots \ldots \ldots$ & & 0.4541 & 0.4541 & 0.4363 & 0.4363 & 0.4542 \\
\hline$C\left(\nu_{6}=1\right) \ldots \ldots \ldots \ldots \ldots$ & & 0.3305 & 0.3269 & 0.3210 & 0.3176 & 0.3233 \\
\hline
\end{tabular}

Perturbation Theory Spectroscopic Parameters $\left(\mathrm{cm}^{-1}\right)$

\begin{tabular}{|c|c|c|c|c|c|c|}
\hline$\omega_{1}\left(a_{g}\right) \ldots \ldots \ldots \ldots \ldots \ldots \ldots$ & 1256.9 & 1306.6 & 1291.6 & 1296.1 & 1280.2 & 1277.0 \\
\hline 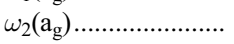 & 938.8 & 989.5 & 981.6 & 976.9 & 969.9 & 927.7 \\
\hline$\omega_{3}\left(b_{1 g}\right) \ldots \ldots \ldots \ldots \ldots \ldots$ & 1024.3 & 1079.1 & 1063.1 & 1073.4 & 1057.5 & 1048.6 \\
\hline$\omega_{4}\left(b_{1 u}\right) \ldots \ldots \ldots \ldots \ldots \ldots$ & 303.2 & 284.3 & 281.6 & 281.5 & 278.8 & 278.8 \\
\hline$\omega_{5}\left(b_{2 u}\right) \ldots \ldots \ldots \ldots \ldots \ldots \ldots$ & 527.7 & 523.1 & 517.8 & 518.0 & 512.6 & 513.0 \\
\hline$\omega_{6}\left(b_{3 u}\right) \ldots \ldots \ldots \ldots \ldots \ldots$ & 1380.6 & 1449.2 & 1435.8 & 1436.5 & 1422.9 & 1421.1 \\
\hline$\nu_{1}\left(a_{\mathrm{g}}\right) \ldots \ldots \ldots \ldots \ldots \ldots \ldots$ & 1248.6 & 1285.9 & 1269.6 & 1277.2 & 1260.2 & 1253.9 \\
\hline$\nu_{2}\left(\mathrm{a}_{\mathrm{g}}\right) \ldots \ldots \ldots \ldots \ldots$ & 926.9 & 949.4 & 939.3 & 941.4 & 931.9 & 928.1 \\
\hline$\nu_{3}\left(\mathrm{~b}_{1 \mathrm{~g}}\right) \ldots \ldots \ldots \ldots \ldots \ldots$ & 998.7 & 981.5 & 968.6 & 976.8 & 963.8 & 956.5 \\
\hline$\nu_{4}\left(\mathrm{~b}_{1 \mathrm{u}}\right) \ldots \ldots \ldots \ldots \ldots \ldots$ & 302.3 & 279.2 & 276.1 & 276.5 & 273.5 & 273.5 \\
\hline$\nu_{5}\left(b_{2 u}\right) \ldots \ldots \ldots \ldots \ldots \ldots$ & 520.2 & 522.5 & 516.9 & 517.7 & 512.0 & 511.7 \\
\hline$\nu_{6}\left(b_{3 u}\right) \ldots \ldots \ldots \ldots \ldots \ldots \ldots$ & 1313.5 & 1378.0 & 1365.1 & 1367.1 & 1354.1 & 1351.5 \\
\hline $2 \nu_{1} \ldots \ldots \ldots \ldots \ldots \ldots \ldots \ldots$ & & 2558.7 & 2526.4 & 2541.5 & 2507.8 & 2495.4 \\
\hline $2 \nu_{2} \ldots \ldots \ldots \ldots \ldots \ldots \ldots \ldots$ & & 1889.5 & 1867.3 & 1874.1 & 1853.9 & 1843.8 \\
\hline $2 \nu_{3} \ldots \ldots \ldots \ldots \ldots \ldots \ldots \ldots \ldots \ldots \ldots \ldots$ & & 1912.4 & 1888.5 & 1903.3 & 1879.2 & 1865.8 \\
\hline $2 \nu_{4} \ldots \ldots \ldots \ldots \ldots \ldots \ldots \ldots \ldots \ldots \ldots$ & & 547.3 & 541.3 & 542.4 & 536.4 & 536.6 \\
\hline $2 \nu_{5} \ldots \ldots \ldots \ldots \ldots \ldots \ldots \ldots$ & & 1023.2 & 1017.6 & 1009.2 & 1003.1 & 1012.4 \\
\hline $2 \nu_{6} \ldots \ldots \ldots \ldots \ldots \ldots \ldots \ldots$ & & 2722.2 & 2696.9 & 2701.0 & 2675.5 & 2670.5 \\
\hline$\nu_{1}+\nu_{6} \ldots \ldots \ldots \ldots \ldots \ldots$ & & 2659.8 & 2629.1 & 2641.7 & 2610.3 & 2598.4 \\
\hline$\nu_{1}+\nu_{3} \ldots \ldots \ldots \ldots \ldots \ldots$ & & 2197.9 & 2171.0 & 2185.2 & 2157.5 & 2145.4 \\
\hline$\nu_{4}+\nu_{5} \ldots \ldots \ldots \ldots \ldots \ldots \ldots$ & & 792.8 & 784.3 & 785.7 & 777.1 & 776.6 \\
\hline
\end{tabular}

${ }^{\mathrm{a}}$ Variational $\operatorname{CCSD}(\mathrm{T}) / \mathrm{cc}-\mathrm{pVTZ}$ calculations.

${ }^{\mathrm{b}} \mathrm{PT} \mathrm{MRCI} / \mathrm{CASSCF} / \mathrm{cc}-\mathrm{pVTZ}$. 
a large basis set. We provide parameters for various isotopomers containing ${ }^{12} \mathrm{C}$ and ${ }^{13} \mathrm{C}$. Anharmonic spectroscopic parameters of the most abundant isotopic varieties are determined with perturbation theory. For this purpose, the quadratic, cubic, and quartic force fields are computed from the six-dimensional potential energy surfaces mapped around the respective local minima. This theoretical work reveals that the frequency calculations allow us to assign the astrophysical observed band to tetracarbon, whereas the argument based on the spin-orbit coupling appears to contradict previous assumptions. Further experimental investigations are needed for the interpretation of the astrophysical observations in connection with similar theoretical investigations on other molecular candidates. The far-infrared spectroscopy should be helpful for these species, which possess zero dipole moment and low bending modes.

This work has been supported by the Ministerio de Educación y Ciencia of Spain through grant AYA2005-00702. The authors wish to acknowledge the Centro de Supercomputación de Galicia (CESGA) for computing facilities. The authors also wish to acknowledge the project "The Molecular Universe: An Interdisciplinary Program on the Physics and Chemistry of Molecules in Space" of the Commission of the European Communities, Marie Curie Research Training Networks, contract MRTN-CT2004-512302.

\section{REFERENCES}

Arnold, D. W., Bradforth, S. E., Kitsopoulos, T. N., \& Neumark, D. M. 1991, J. Chem. Phys., 95, 8753

Botschwina, P. 1997, J. Mol. Spectrosc., 186, 203 2006, Chem. Phys. Lett., 421, 488

Cernicharo, J., Goicoechea, J. R., \& Benilan, Y. 2002, ApJ, 580, L157

Cernicharo, J., Goicoechea, J. R., \& Caux, E. 2000, ApJ, 534, L199

Douglas, A. E. 1977, Nature, 269, 130

Dunning, T. H. 1989, J. Chem. Phys., 90, 1007

Forney, D., Jacox, M. E., \& Thompson, E. E. 1995, J. Mol. Spectrosc., 170, 178

Gakwaya, S., Abusara, Z., \& Moazzen-Ahmadi, N. 2004, Chem. Phys. Lett., 398,564

Heath, J. R., \& Saykally, R. J. 1991, J. Chem. Phys., 94, 3271

Hoy, A. R., Mills, I. M., \& Strey, G. 1972, Mol. Phys., 24, 1265

Kella, D., Zaifman, D., Heber, O., Majer, D., Feldman, H., Vager, Z., \& Naaman, R. 1993, Z. Phys., 26, 340

Knowles, P. J., Hampel, C., \& Werner, H.-J. 1993, J. Chem. Phys. 99, 5219 (erratum 112, 3106 [2000])

Knowles, P. J., \& Werner, H.-J. 1985, Chem. Phys. Lett., 115, 259 . 1988, Chem. Phys. Lett., 145, 514

Lefebvre-Brion, H., \& Field, R. W. 2004, The Spectra and Dynamics of Diatomic Molecules (Amsterdam: Elsevier)

Linguerri, R., Navizet, I., Rosmus, P., Carter, S., \& Maier, J. P. 2005, J. Chem. Phys., 122, 034301
Martin, J. M. L., Schwenke, D. W., Lee, T. J., \& Taylor, P. R. 1996, J. Chem. Phys., 4, 4657

Massó, H., Senent, M. L., Rosmus, P., \& Hochlaf, M. 2006, J. Chem. Phys., 124,234304

Moazzen-Ahmadi, N., \& Thong, J. J. 1995, Chem. Phys. Lett., 233, 471

Moazzen-Ahmadi, N., Thong, J. J., \& McKellar, A. R. W. 1994, J. Chem. Phys., 100, 4033

Shen, L. N., \& Graham, W. R. M. 1989, J. Chem. Phys., 91, 5115

Smith, A. M., Agreiter, J., Hartle, M., Engel, C., \& Bondybey, V. E. 1994, Chem. Phys., 189, 315

Szczepanski, J., Ekern, S., Chapo, C., \& Vala, M. 1996, Chem. Phys., 211, 359

Tam, S., Macler, M., \& Fajardo, M. E. 1997, J. Chem. Phys., 106, 8955

Van Orden, A., \& Saykally, R. J. 1998, Chem. Rev., 98, 2313

Watts, J. D., Gauss, J., Stanton, J. F., \& Bartlett, R. J. 1992, J. Chem. Phys., 97, 8372

Werner, H.-J., \& Knowles, P. J. 1985, J. Chem. Phys., 82, 5053 1988, J. Chem. Phys., 89, 5803

Werner, H.-J., et al. 2002, MOLPRO: A Package of Ab Initio Programs, version 2002.1 (Birmingham: Univ. Birmingham), http://www.molpro.net

Withey, P. A., Shen, L. N., \& Graham, W. R. M. 1991, J. Chem. Phys., 95, 820

Xu, C., Burton, G. R., Taylor, T. R., \& Neumark, D. M. 1997, J. Chem. Phys., 107,3428 